\title{
Business and Naturalism
}

\author{
A Peek at Transcendence?
}

TIMOTHY L. FORT

University of Michigan

\begin{abstract}
Bill Frederick's work calls on business ethicists to consider religion as well as nature. Because there are naturally wired religious impulses in human beings and because of the fairness of including normative approaches meaningful for business people, Frederick suggests that the "R" in $\mathrm{CSR}_{4}$ should represent religion. This article takes up the theme in terms of the emerging field of naturalist theology, particularly (although embryonically) as stated by theologian Paul Tillich. Doing so creates (a) connections between "God as Life" and nature and (b) linkages of the notions of symbol, culture, and transcendence. In addition to avoiding the socalled "naturalistic fallacy," this integration can foster ethical business behavior.
\end{abstract}

\section{INTRODUCTION: FREDERICK, BUSINESS, AND RELIGION}

Bill Frederick's work is a significant departure from the philosophical tradition of business ethics. Whereas Frederick relates to and hopes to integrate his work with philosophical business ethics, his point of departure is the radically different source of science (Frederick, 1995). For Frederick, nature is the substance of that with which we survive and think. Reflecting on the meaning of that substance provides insights as to what we should do.

I have elsewhere provided a more detailed analysis of Frederick's work (Fort, 1997) and shall not repeat it here. Instead, I would like to take Frederick up on an invitation that he first implied in his book Values, Nature, and Culture in the American Corporation and then explicitly extended in his address to the Social Issues of Management Section of the Academy of Management (SIM), revised and published in this journal (Frederick, 1998). In his book, Frederick notes convergence among world religions

BUSINESS \& SOCIETY, Vol. 38 No. 2, June 1999 226-236

(C) 1999 Sage Publications, Inc. 
around central moral principles, in some sense similar to the work he did in his article on transnational codes (Frederick, 1991). The implication is that dialogue with and among world religions may produce insights for relevant moral principles in business.

Frederick went further in his 1996 SIM address. In it, he proposed three directions for corporate social responsibility (CSR, in Frederick's terms): an increasing awareness of the cosmological ("C" in $\mathrm{CSR}_{4}$ ) processes of all life, including business (Frederick, 1998, pp. 45-47), and the increasing importance of science ("S" in $\mathrm{CSR}_{4}$ ) in understanding these natural processes (Frederick, 1998, pp. 47-49). A third is an increased emphasis on the phenomenon of religious belief ("R" in $\mathrm{CSR}_{4}$ ) in business (Frederick, 1998, pp. 49-54).

He provides several reasons for emphasizing religion. Most important, he argues that, like it or not, human beings have a "metaphysical impulse" rooted in neurological processes that generate a "constant stream of symbolic-creative-imaginative-curiosity-play impulses" (Frederick, 1998, p. 50). These impulses lead to an inquiry of what a person's place in the natural order might be (Frederick, 1998, p. 51). In short, it leads to religion. Frederick is careful to point out that he is not arguing that this should be the case, only that it is the case and has to be taken into account (Frederick, 1998, p. 51).

More normatively, he notes that on grounds of legitimacy, fairness, and honest disclosure, it may be worth considering that a person with strong religious beliefs should be entitled to rely on those beliefs in making a business decision and to also rely on those beliefs in justifying the decision. Noting, though not endorsing the whole of Laura Nash's work on evangelical CEOs (Nash, 1994), he points to the fact that many business leaders do in fact have strong religious beliefs and those beliefs may have a positive impact on the ethicality of the business (Frederick, 1998, p. 52). Underlying each of these rationales is the conviction that religion is an undeveloped resource for motivations to practice ethical business behavior and for finding cross-cultural moral principles.

There are dangers in opening this door. As Hume noted, "errors in religion are dangerous; those in philosophy only ridiculous" (Bell, 1779/1990, p. 30). Theologians often agree. Stanley Hauerwas (1983) argues that once one thinks one knows what is "natural" then one can much more easily punish, perhaps even torture, something or someone who is "unnatural" (p. 61). Moreover, Frederick (1998) himself warns that natural processes dictate no one religious dogma: 
One should not count on finding your own religious Philosophy written on the face of the cosmos. Rather, what can be counted on is a personal need to make the search [for cosmic meaning]. Some people create their own meaning; for them, personal significance is not out there awaiting discovery. Most people fall short of this kind of religious creativity and simply accept the metaphysical meanings given to them by their culture. (p. 51)

This article argues that when linked to contemporary notions of naturalist theology, we will find ourselves in a position in which (a) there is a transcendent good to which all business persons are accountable, (b) the fate of business persons is that of freedom and choice of wrestling with difficult moral issues, and (c) business persons become responsible for integrating the various elements of life, including ethics in business. Before making this argument, two important delimitations are necessary.

First, this article runs a great risk of making no one happy. To philosophers, adding religion to Frederick's already controversial naturalism could be like throwing gasoline on a fire. To those with strong religious convictions, naturalist theology can come across as flabby and pantheistic. This article, however, neither seeks to challenge philosophy nor to evangelize. Instead, it seeks to use natural theology's increasingly sophisticated integration of religion and science to make applied philosophy more relevant and to identify this basic transcendence that religions interpret diversely. Second, this article does not provide a comprehensive analysis of naturalist theology or of naturalism, or of the relation between these approaches and corporate bureaucracy. It only suggests why some beginning integration might be fruitful.

\section{FREDERICK AND TILLICH}

\section{Frederick's Methodology}

The methodological heart of Frederick's naturalist approach is to argue that in all life, there are three distinct value clusters (Frederick, 1995, pp. 7-14). Economizing is the conversion of raw materials into materials that sustain us. Individually, that is the process of metabolism. The conversion of materials into products and services is a business "extrusion" of this value (Frederick, 1995, pp. 27-56).

Power-aggrandizing values are quests for power, status, and recognition. Rooted in natural processes (a lion becoming "king" of a pride is an 
example, although one not used by Frederick), power-aggrandizing is always associated with hierarchies and suppression of the abilities of those who do not have power. Frederick is very negative about the consequences of leaving this element unchecked in business (Frederick, 1995, pp. 57-78).

The third value cluster is comprised of ecologizing values. These values are the complex webs of relationships and interdependencies that sustain communities of life. All life depends on these interlinkages, and they have long-range evolutionary adaptivity. Undermining such communal links undermines the species itself (Frederick, 1995, pp. 134-167).

Any biologically based moral approach risks the attack of determinism. Frederick avoids this dilemma by arguing that our biologically rooted ability to think symbolically and abstractly allows us to invent and create. These are "technologizing values." Some inventions can be gadgets, as the term technology is typically used. But Frederick conceives of this creative aspect of humanity more broadly as the ability to integrate, innovate, design, and reflect.

Frederick also has specific words to say about naturalism's significance for business ethics. Perhaps the most significant difference between Frederick and the philosophical approaches is that because Frederick views economizing values as significant, natural elements to life, he is more concerned with giving stakeholders the ability to participate in decisions than he is in constructing principles and structures of distributive justice or individual rights. The latter he characterizes as being anachronistically applied to contemporary life, and the former undermines the individual's participation in control of his or her own life (Frederick, 1995, pp. 251-257).

A second important difference is Frederick's comfort in cultural relativism. Cultures (and individuals) reflect on nature and specify norms appropriate for them. They do so in different ways, and such diversity is an evolutionary advantage rather than a disadvantage. Just as diversity sustains both botanical and zoological communities, so human cultural diversity ought not be replaced by universalizing tendencies found, he argues, in western philosophy (Frederick, 1995, pp. 249-250).

This, of course, poses a dilemma. If cultures interpret a transcendent nature differently and that is an advantage, then why search for convergence of moral traditions? The short answer is that nature also limits human inventiveness of describing what ought to be. It may be true that there are few absolutes, but not everything is allowed. 


\section{Frederick and the Naturalistic Fallacy}

For any naturalist theory, it is necessary to confront Hume's so-called "naturalistic fallacy." The fallacy, of course, is that one cannot derive an "ought" from an "is." Several things can be said about the fallacy. I will limit myself to two: Hume is right and Hume is wrong.

Every business ethicist has been confronted at some point with the argument of "that's just the way things are" from a student, colleague, or businessperson. This argument could justify a whole laundry list of distressing actions. Beyond such a weak form of the fallacy, Hume was after theologians whose religious dogma ultimately relied on a descriptive rather than a normative argument. Frederick, recognizing the correctness of this argument, says that a description of a tripartite life does not tell us what to do. We should not follow a model of nature; nature provides many models. Furthermore, we ought not attempt to replicate any particular cultural articulation of a natural model.

Hume is wrong, however, if this position means that "what is" does not have a great deal to do with "what ought to be." Nature does constrain what we ought to do. More importantly, Hume is also wrong if our ability to construct an "ought" is the quality that allows us to reach toward a cosmological essence that lies beyond our particularity. At that point, "ought" is an expression of "is." The naturalist fallacy has its greatest weight when "ought" is confused with an attempted universalization of a particular normative form, but is weightless when "ought" stands beyond the particular form.

Frederick invites us to see if we can preserve the "is" from which we drive the "ought" without confusing the language of the "ought" for what "is." In other words - and not in Frederick's words-Frederick asks us to see if religion can motivate ethical business behavior and thereby make business life meaningful while keeping a cosmological essence free from being captured by any one theological tongue.

If nature is the transcendent reality of our existence from which we develop who we are, then what we ought to be is simply part of our extended nature. Paul Tillich (Taylor, 1946/1987) puts this theologically when he writes,

The superior law is, at the same time, the innermost law of man himself, rooted in the divine ground which is man's own ground: the law of life transcends man, although it is, at the same time, his own. (p. 121) 
In this formulation, what ought to be is a subset of what is. The particular form of this subset, however, varies according to culture and community. This means that there is an existentialist, autonomous point where the question of what ought to be is made within the community to which one belongs and with regard to a transcendent reality.

Tillich and Naturalist Theology

There are others who have done more significant work in natural theology than Paul Tillich. Pierre Teilhard de Chardin, Wolfhart Pannenberg, and the members of The Institute of Religion in an Age of Science have far more specifically tied religious impulses and cosmological belief to the realities of scientific discoveries. Tillich's theology is particularly open to Frederick's work, however, and may serve as a bridge to more complex integration of nature, religion, and business. Thus, for purposes of illustration, his work will be used to show how a naturalist grounding of theology meets the goals of Frederick's quest.

First, Tillich (Taylor, 1946/1987) makes a distinction between naturalist theology and theology of the natural. The term naturalist theology is misleading, he argues, because, at least in terms of ethics, we live in terms of culture (p. 39). It is through culture that we learn our moral duties, not through an unmitigated revelation through nature, although nature can provide such insight (pp. 163-164). Thus, as seen in Frederick's work, nature may be transcendent, but we experience it through the communities in which we live.

What, then, is this nature and what is God's relation to it? For Tillich, God is Being. God is not "a" being, but God is power that transcends all beings and the totality of beings. God is the ground of being and God is the structure of being (pp. 163-166). God is not a grand old man sitting up in heaven, but is more like a Buddhist enervating force that supports, structures, and moves through all beings. Religion, then, is directedness toward this unconditional, transcendent element (p. 40). God, in a very real sense, is the phenomenon of life and religion is a particular group's experience with that phenomenon.

Tillich's God sounds a great deal like Frederick's nature. For both, $\mathrm{God} /$ nature is that which is life and because that God/nature is a certain structure, there are lessons we can learn by reflecting on that structure. The structure or force is not embodied fully in any particular culture, but particular communities structure themselves according to their experience with and reflection on it. 
There are more specific corollaries. Frederick emphasizes, as we have seen, the human ability to use symbols. This ability is the heart of technologizing values. Theologically, this ability to grasp and to use symbols emphasizes the meaningfulness of business activity. Symbols, according to Tillich, "are directed toward the infinite which they symbolize and toward the finite through which they symbolize it" (p. 168). Our work in business attempts to make sense of such work in light of a transcendent reality and empowers our work as a symbol. In this light, business is not only a (technologizing) symbol of Frederick's value clusters, but business becomes important and meaningful because of what it reflects. In short, business is not "just business" but links existential work to transcendence itself.

There is a second, important symbol that we have seen: the notion of participation. Its "meaning" lies in the fact that the transcendent participates in life (Taylor, 1946/1987, p. 172). This leads to the notion of God as Person, because people participate. That is the symbol. The meaning behind the symbol is that there is human interaction with the transcendent because the ground of being, God/Nature, is a participating force in lives.

A third important symbol is destiny. For Tillich, secular culture is troubled by the fact that it has no teleology directing it or toward which it is directed. Religion, however, deepens the meaning and purpose of culture by tying it to a transcendent reality (pp. 123-125). Such a teleology shapes our destiny that emphasizes our particularity and individuality. To lose teleology causes us to lose the meaningfulness of life (p. 162).

There is one final point to make about this all too brief reprise of Tillich's thought. Because of his understanding of the particularity of culture, Tillich is quite open to other religions. Indeed, he describes the revelation of this God-as-Being as "universal" (p. 316). Thus, the type of convergence work Frederick describes is not only an interesting phenomenon of what people share, but a revelation of transcendence itself. Thus, three main themes for Tillich-God as the being of life, symbol (with elements of meaningfulness, participation, and destiny), and culture-describe a transcendent force of life whose presence dramatically raises the stakes of business ethics.

\section{So What?}

Noting overlaps is only a moderately persuasive reason to admit theology to business ethics discussion. One could respond, and many do, why admit such controversial notions when one can talk about ethics or even 
nature without it? This response does not get very far either. Those who would rather keep the religious voice quiet may see little reason to admit it, but others might equally see the voice as valuable. In fact, if there is a "metaphysical impulse" practiced diversely, then there is a critical need for multiple moral languages. No side needs to convert others to using any one language. Overlaps suggest a point for agreement of what ought to happen, whereas different languages provide ownership for the speaker of why that action is personally meaningful.

If I read Frederick's invitation correctly, this is very much his point. Speaking in a religious language as well as a secular one allows a person to connect with a meaningful source. Some business persons may not see why Rawls is compelling in requiring consideration of the health conditions of factory workers, but understand the same obligation through the parable of the Good Samaritan. Similarly, many business persons are fond of applying Darwinian analogies to business. Showing a moral side to nature, as Frederick and naturalist theology do, speaks in a language more difficult for a competitive business person to dismiss than Kant.

A theology of nature also poses a challenge to religions that absolutize their dogma. The more one can find corollaries and common ground among religions and with nature, the harder intolerance is to practice. Though I am not naive about the risks of linking theology and nature, doing so may enhance the motivation for being ethical in business while limiting the likelihood of intolerance.

Naturalism and naturalist theology provide a rationale for why business ethics matters. They do so by linking the importance of moral behavior in terms of transcendence and personal meaningfulness.

\section{TRANSCENDENCE AND MEANINGFULNESS}

Having described this transcendent reality in terms that link theology and Frederick, the next question is what, if anything, this has to say about business ethics. ${ }^{1}$ One can identify three major themes in which the reality of transcendence makes ethics a necessary component of business.

First, as Dostoyevsky asked, if there is no God, then is crime inevitable? Dostoyevsky's argument was that human determination of the good was insufficient if unhinged from a transcendent reality. In business terms, business persons often think that any activity is allowed provided it does not violate the law (and sometimes not even then). This view considers economizing values and, to the extent that the law can be characterized as an instrument of power, power-aggrandizing values. It says nothing about 
what is necessary to build a community of people living together. Frederick's naturalist transcendent reality argues that business is not exempt from community-building realities. This need is why ethics is critical to business. To the naturalist theologian, business is subject to the being, the life force, that is God. Some research indicates that reciprocity is a universal norm (Wattles, 1996) and that its practice is biologically disposed toward (Dunbar, 1997) and enhanced in small "mediating institutions" (Berger \& Neuhaus, 1977). Business then becomes a symbol for opening up human lives to the transcendent reality of the natural need for community and raises the stakes of business itself. Cultures and individuals do vary and therefore many values are relative, but not everything is allowed.

A second theme is that of freedom. Our technologizing efforts of innovation, creativity, and reflection are not simple tasks. In business terms, this human freedom is double-edged. Business persons and business students ask for a great deal of freedom. They want to be free of many things, including governmental and moral constraints. But they also often want business ethicists to tell them what the right "rule" is and become quite unhappy when the professor responds with a way to analyze the problem rather than providing a fast rule.

If, however, our very being is that of a transcendent participation in life and in creatively responding to the openness of the opportunity to participate in life, then we must also be autonomous creatures, at least to some degree. Our ethics are not determined, nor are we to be rote-like followers of oppressive hierarchical regimes, but nature provides us with technologizing capabilities that require us to accept an existential challenge of choice.

The third theme is responsibility. Executives foster a culture, create incentives for certain kinds of behavior, and even give orders, but often when the consequences of those orders are negative, they maintain "plausible deniability" so they will not be blamed. But if one does not integrate the transcendent elements of life, then one is subject to the participation of that element regardless of whether one likes it or not. In Biblical times, this would be known as God's punishment. A less dramatic but no less painful example is acid rain being the natural result of pollution. In short, nature ultimately demands responsibility.

Business is thus subject to universal moral laws of a transcendent good, of having to wrestle with tough ethical choices, and of being responsible. Transcendence requires choice and responsibility; it does not determine behavior. Transcendent being and nature thus mandate an integration of values because transcendent reality participates in life itself. 
Transcendence raises the stakes of business activity; freedom and participation make individual effort meaningful.

\section{CONCLUSION}

Bill Frederick demonstrates that there are certain natural forces to which we are all subject. In that sense, nature is transcendent. We are all subject to it. We must all deal with it. In many respects, nature deals with us when we have not properly dealt with it.

Religion can augment this approach. First, religion can link insights about transcendence with other moral traditions around the globe, and by doing so gain a greater understanding of the transcendent itself. (This is the notion that there is a universal, transcendent being that sets limits for what business can do.) Second, it provides meaning-making for individuals to understand why ethical behavior is important in relation to transcendent demands and insists that business persons are responsible for integrating the competing forces of life; they are not simply to follow a simple rule. (This is the notion of participation and responsibility.)

Bill Frederick has harnessed a tremendously complicated body of knowledge. He challenges Darwinian analogies to business by demonstrating that nature is more complex. In doing so, he opens the door for many kinds of future interdisciplinary interchanges. This has been the beginning of one such interchange. But many others await, and I welcome dialogue with them.

\section{NOTE}

1. Although this may seem far afield, I would like to make this connection in terms of Dostoyevsky's The Brothers Karamazov (1880/1990). I show the movie version of this novel to my business ethics class each term because its themes are directly relevant to business and are directly related to the prior discussion (Fort, 1998). The Brothers Karamazov, as all Russian novels, is complicated and explaining exactly how the movie or the novel gets to these three themes will be too distracting from the purpose of this article.

\section{REFERENCES}

Bell, M. (Ed.). (1990). David Hume: Dialogues concerning natural religion. New York: Penguin Press. (Original work published 1779) 
Berger, P., \& Neuhaus, R. J. (1977). To empower people: The role of mediating structures in public policy. Washington, DC: American Enterprise Institute.

Dostoyevsky, Fyodor (1880). The brothers Karamazov. Trans. Richard Pevear \& Larissa Volokhonsky (1990). New York: Vintage Press.

Dunbar, R. (1997). Grooming, gossip, and the evolution of language. Cambridge, MA: Harvard University Press.

Fort, T. L. (1997). Naturalism and business ethics: Inevitable foes or potential allies. Business Ethics Quarterly, 7, 149-163.

Fort, T. L. (1998). The Brothers Karamazov ethics and responsibility. In O. F. Williams (Ed.), The moral imagination: How literature and films can stimulate ethical reflection in the business world. Notre Dame, IN: University of Notre Dame Press.

Frederick, W. C. (1991). The moral authority of transnational corporate codes. Journal of Business Ethics, 10, 165-177.

Frederick, W. C. (1995). Values, nature, and culture in the American corporation. New York: Oxford University Press.

Frederick, W. C. (1998). Moving to CSR4: What to pack for the trip or the dinosaur's next footprint. Business \& Society, 37, 40-59.

Hauerwas, S. (1983). The peaceable kingdom: A primer in Christian ethics. Notre Dame, IN: University of Notre Dame Press.

Nash, L. L. (1994). Believers in Business. Nashville: Thomas Nelson, Inc.

Taylor, M. K. (Ed.). (1987). Paul Tillich: Theologian of the boundaries. Minneapolis, MN: Fortress. (Original work published 1946)

Wattles, J. (1996). The golden rule. New York: Oxford University Press.

Timothy L. Fort is an assistant professor at the University of Michigan Business School. Fort received his J.D. and Ph.D. from Northwestern University. His Ph.D. is in theology with a business cognate. He received his M.A. and B.A. from the University of Notre Dame. He received the 1998 Junior Faculty Award of Excellence from the Academy of Legal Studies in Business and is the only person in ALSB history to win consecutive Outstanding National Conference Proceedings Paper Awards. He also runs a family agribusiness concern in Illinois. 